Results Experts recorded (con)structural upgrades in the course of the generation of a school route map and claimed the maps to be of help in road safety education. $65 \%$ of the questioned parents indicated that they got the map at start of school, although every year one pupil should get one, and only $10 \%$ really used it. To improve the usage they recommended handing out the plan already in Kindergarten. In contrast, about $70 \%$ of the headmasters of schools with school route maps stated that the map is used in road safety education. They saw the major problem in the annual reprint. Of the schools without a map $86 \%$ didn't know such maps are existing and about 50\% declared that they would be interested. The accident analysis revealed no significant changes in the accident rate as well as in the casualties since the introduction of school route maps.

Conclusions Regarding the accident rate no success of Austrian school route maps could be proven. However, experts and headmasters stated positive experiences. Overall seemed to be room for improvement. One of the first steps would be to make school route maps more known, and to hand them out to parents of year one pupils earlier and yearly (e.g. on school registration day).

\section{PERCEPTION OF UNINTENTIONAL CHILDHOOD INJURIES AMONG RURAL MOTHERS IN SOUTH INDIA}

'Leeberk Raja Inbaraj, ${ }^{2}$ Anuradha Rose, ${ }^{2}$ Kuryan George, ${ }^{2}$ Anuradha Bose. ${ }^{1}$ Bangalor Baptist Hospital, Bangalore, India; ${ }^{2}$ Christian Medical College, Vellore, India

\subsection{6/injuryprev-2016-042156.651}

Background Parental perception of safe and risk-free environment is critical in the prevention of unintentional childhood injury. An accurate perception of risky situations is essential to minimise the rate of childhood injuries. Knowledge on parental perception in rural India will be helpful in planning preventive strategies. This study was conducted to assess parental perception on risks and hazards leading to unintentional childhood injuries.

Methods A cross sectional study was conducted in 13 clusters of a rural block in South India. Double stage cluster sampling method was used to recruit 100 mothers and they were interviewed using a tool developed by Glik and Kronenfeld. Two FGDs were also conducted.

Results Mothers' perception of likelihood of injury from hazards such as household door and drawers, small toys, plastic bags and cribs was poor. These objects were also perceived as less dangerous hazards. Mothers had a poor perception of injury by entrapment in refrigerators, choking and strangulation by a rope or a cord. Choking bruises, puncture wounds were perceived as less serious events. Age, education and literacy were found to be significant predictors of perception of risk and hazard in univariate analysis, the logistic regression model did not show any significant associated factors for perception of risk and hazard. $9 \%$ of mothers believed injuries can be completely prevented and illiteracy $(\mathrm{p}=0.04)$ was associated with poor perception on prevention in univariate analysis. Few mothers in FGD believed that injuries cannot be prevented as it is natural (Vidhi) for children to sustain injuries.

Conclusions It is a fact that the mother's literacy and schooling is closely related to child health and survival. Promotion of injury preventive engineering strategies and enforcement will only be effective when the literacy of the mother increases. Health education can improve maternal perception and have a positive impact on prevention of unintentional injuries.

\section{STRENGTHENING A CULTURE OF SAFETY FOR CHILDREN: DEVELOPING HOSPITAL AND COMMUNITY COLLABORATIONS}

Nan Peterson, James Savage, Nicole Vesely, Rishelle Eithun. UW Health American Family Children's Hospital, USA

\subsection{6/injuryprev-2016-042156.652}

Background Unintentional injury is the leading cause of death and disability for America's children. The economic consequences of injury are staggering; with injury being the leading cause of medical spending for children ages $5-14$ in Wisconsin. As a health care system, we see the consequences of preventable injuries. As a children's hospital we have an obligation to lead the way in modelling best practice, evidence-based injury prevention strategies for children in collaboration with our community partners.

Methods/approach Review of Wisconsin paediatric injury and death data formed the basis of prioritising program development or system-level strategies for injury prevention. Using a policy, systems, environmental approach, we identified best practice injury prevention strategies with our community partners. By implementing a collective impact model and community engagement, we formulated plans for improving the injury prevention strategies for children and families in our community.

Results Examples related to child passenger safety, home visitor program, a safe sleep campaign, Safety Town, and a "safety store" will be provided. Program barriers and challenges, as well as successful outcomes in strengthening the culture of injury prevention through community engagement will be shared.

Conclusions Health care providers and community partners are looking to embrace population health strategies to achieve a greater good for improving the health of children. Using a collective impact model enables communities to accelerate the progress they can have in reducing childhood injury related morbidity and mortality. Safety devices, when correctly used, are highly effective in preventing injuries and saving lives. Recognition of the need to reduce health disparities by removing potential social, economic and language barriers for families around injury prevention strategies is critical.

\section{SAFETY FOR YOUTH INVOLVED IN COMMUNITY BASED AGRICULTURE}

Marsha Salzwedel, Bryan Weichelt, Casper Bendixsen, Barbara C Lee. National Children's Centre for Rural and Agricultural Health and Safety, Marshfield, WI, USA

\subsection{6/injuryprev-2016-042156.653}

Background As Community Based Agriculture (CBA) gains popularity in the U.S., more youth are becoming involved. One type of CBA is Community Supported Agriculture (CSA). In CSA, farms sell shares of their harvest, which may include customer labour: as part of the share, to reduce the price of the share, or to gain extra product. Another form of CBA is public gardens (e.g., community, urban, school). Adults work with youth to plant, weed and harvest. Often, those working in CBA are not familiar with the tasks, equipment, and hazards. There are no known safety resources for youth involved in CBA, thus adults depend on prevention strategies from various disciplines to address common problems such as bee stings or weather-related hazards.

Methods A pilot study was undertaken to assess youth safety in CBA. A survey was sent to a convenience sample of community/ 